\title{
Health workers murdered as Pakistan vaccinates 8.4 million children
}

$\mathrm{D}$ espite an army of police, vaccination workers in Pakistan are still being murdered in the midst of a public health initiative aimed at vaccinating 8.4 million children in one province against polio and several other diseases in just three months.

The Health for All vaccination program, which runs Feb. 2 through April, targets indigenous wild poliovirus, which is still endemic in Pakistan, Afghanistan and Nigeria. Of the three countries, only Pakistan is seeing an increase in cases. In January 2014, the World Health Organization (WHO) declared Peshawar, the capital of Khyber Pakhtunkhwa province, "the world's largest reservoir of endemic poliovirus."

In 2012, there were 58 cases of polio in Pakistan; by 2013, there were 91, according to WHO. Of these, 83 were genetically linked to strains in Peshawar. The disease, which is spread by fecal contact, is highly infectious and can cause irreversible paralysis.

Vaccination efforts have been seriously stalled by the murder of at least 35 health workers who had been attempting to vaccinate children since 2012. Militants are suspicious of vaccinations, which radical clerics claim are part of a Western plot to sterilize Muslims.

Under Pakistan's Health for All campaign, 5500 police are guarding the vaccinators, says public health physician Dr. Ahmed Ali. The security appeared to have proved effective against the Taliban, adds Dr. Jan Baz Afridi, head of the Khyber Pakhtunkhwa vaccination program.

Nonetheless, on Mar. 2 in southwest Peshawar, 13 people were killed in a roadside attack on a vaccination team, including 12 guards and a child. Two Pakistani polio vaccination teams of six apiece were abducted earlier this year; one team has been released, the other is still missing. And on Mar. 24, a woman working on the vaccination project was

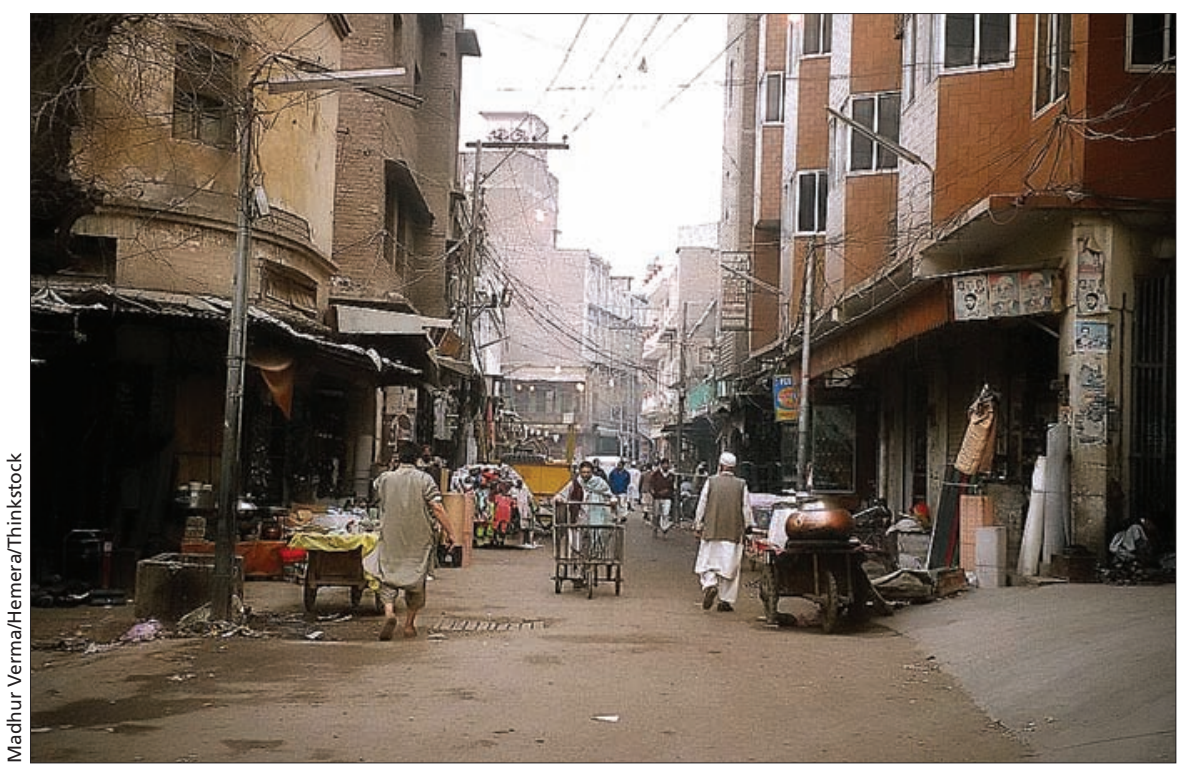

The city of Peshawar has been declared "the world's largest reservoir of endemic poliovirus" by the WHO.

kidnapped, tortured and murdered. It is not known who is behind the murders or abductions.

Under the program, 700000 children in and around Peshawar are being vaccinated every Sunday for 12 weeks. The eight rounds conducted so far have gone well, said Dr. Elias Durry, WHO's Senior Coordinator for Polio Eradication in Pakistan. Recent water samples have tested negative for poliovirus for the first time in two years due to the mass immunization.

The program will be extended to the remaining three districts of the province in April. The cost of more than \$2 million is supported by WHO, UNICEF and the Bill \& Melinda Gates Foundation.

About 12000 workers, many of whom are members of the local community, are vaccinating children against polio and several other preventable childhood diseases: tuberculosis, diphtheria, pertusis, tetanus, hepatitis $\mathrm{B}$, hemophilus influenza, pneumonia and measles. For the first time in Pakistan, parents are being offered a monetary incentive of $\$ 11.30$ for each newborn child who com- pletes the 15-month vaccination program.

According to Pakistan's government, $27 \%$ of deaths in children under five are due to vaccine-preventable diseases. Currently, only $47 \%$ of children are vaccinated against measles, which has been causing 15 deaths on average every month. The immunization rate will be scaled up to $80 \%$ in one year under the program. The workers also distribute hygiene kits in slums to help prevent water- and food-borne diseases, and they deliver public health messages aimed at preventing diseases such as hepatitis, dengue and bird flu.

In addition to an army of health care workers, Pakistan has engaged legendary cricketer Imran Khan to lead the Health for All program. Khan said he is upbeat about the outcome. "We have eliminated the virus from Peshawar, which used to transmit [the] virus to [other] countries, including Syria, Egypt, China and Afghanistan."- Ashfaq Yusufzai, Peshawar, Pakistan

CMAJ 2014. DOI:10.1503/cmaj.109-4776 